in sarcoidosis and the normal levels. A further study of this interesting condition is called for especially in view of the evidence (reviewed by Drs. Willoughby and Mitchell) that Crohn's disease and ulcerative colitis may sometimes share so many features that the distinction between them has become blurred.-We are, etc.,

E. A. Caspary E. J. FIELD

M.R.C. Demyelinating Diseases Unit,

University of Newcastle upon Tyne

\section{Safety with Lasers}

SIR, - With reference to your leading article on "Safety with Lasers" (3 July, p. 3), may I be allowed to make the following points?

A determination of damage threshhold has been carried out in a human eye using a 1 msec ruby pulse and found to be $2.6 \times 10^{-4}$ joules incident on the iris. Unfortunately the ophthalmic surgeon failed to nore the iris aperture area and so this figure cannot be converted into joules $/ \mathrm{cm}^{2}$ incident energy.

You mention the need for immediate examination following laser injury. May I point out that several cares of delayed lens cataract have been reported and that a need for follow-up examination may exist. The source of cataract generation has not, to my knowledge, been determined, but is most likely shock wave polymerization.

Cases have arisen of laser laboratory personnel having congenitally defective vision in one eye. For their safety, we have recommended a change of occupation. The cooperation of ophthalmic surgeons carrying out the preliminary eye test is of paramount importance in such cases.

The present cost of regular ophthalmic investigation precludes the widespread commercial use of lasers to some conciderable extent. In many cases, methods can be devised for complete separation of personnel from lasers but a need does arise for a simplified code of practice if the laser is to become a commercial viable tool.-I am, etc.

Department of Physics,

D. W. Goodwin University of York,

York

\section{Pregnancy Advisory Services}

SIR,-There can be no doubt that the Abortion Act is variously interpreted by doctors, and conditions which satisfy one that termination of pregnancy is required will not satisfy another. Since the operation is actuglly performed by gynaecologists their differing oninions are of most consequence and make for widely differing opportunities for abortions under the National Health Service in different areas. Many patients have to have the operation carried out privately in cities far away from home.

I feel there is a need for local authorities to set up advisory services on the lines of the Birmingham Pregnancy Advisory Service, a voluntary organization. Here al women with an unwanted pregnancy can seek advice, either through referral by their general practitioners or directly. If the patient fulfils the necessary conditions for termination the required forms are completed and she is referred to a sympathetic gynaecologist, privately if necessary. The doctors who staffed such a service would obviously become familiar with the views of the gynaecologists in the area, and if necessary with those in surrounding areas and those running private nursing homes for abortion cases.

Where termination of pregnancy was not recommended, any necessary arrangements for social support could be put into action.

There must be many doctors who believe in the ideal of the Family Planning Association "every child a wanted child" and would be willing to staff such a service. By referring to gynaecologists only cases where two medical recommendations for termination of pregnancy have been obtained gynaecologists would be spared much formfilling, which I believe many find irksome. In rural areas and small towns the service could well be combined with a local authority family planning service.

The turnover of the Birmingham Pregnancy Advisory Service is ample proof of the demand for an advisory service. There may well be other such voluntary organizations in existence of which I am not aware. They would all no doubt be only too happy if statutory bodies would take over their function. The service need not necessarily be free. I am sure that patients would not be discouraged by a fee.-I am, etc.

Lincoln

BARBARA BRUMBY

\section{Working of the Abortion Act}

SIR,-The arguments over termination of pregnancies following the passage of the Abortion Act continue unabated. I have long found that the public have no knowledge that certain criteria have to be fulfilled before a pregnancy can be legally terminated, and where there is any doubt I have always asked patients to read the four clauses on the green form and requested their personal opinion. Whenever they have considered one of these clauses to apply to them I have referred the patient to the appropriate specialist, be it medical social worker or psychiatrist or physician, though I have always believed that there is practically never a purely obstetric or gynaecological indication for the termination of a pregnancy.

I feel that, in view of the present committee which is investigating the working of the Abortion Act, the time has come when gynaecologists should only have to include in their routine hospital practice those cases where there is a true medical indication for the operation. If Parliament really accepts that the public should have the service provided by the private nursing homes surely it would be more politically honest that they should alter the wording of the Act to indicate this, and at the same time provide the centres where this can be done. If they consider that some fine or deterrent is needed to dissuade people from becoming pregnant irresponsibly then they could impose a charge for the operation, perhaps adjusted by a means test. Operations carried out in other institutions could then be made illegal and so we might eradicate from our profession the stigma that has attached to us.-I am, etc.

\section{Starvation Therapy in Obesity}

SIR,-Dr. F. Cavagnini and others (29 May, p. 527) support starvation therapy in obesity.

As a prisoner of war in the second world war I dealt with malnourished men, and was myself subjected for a period to almost complete starvation. The main consequence of lack of food was infection, particularly pulmonary tuberculosis. Deaths probably did occur from malnutrition per se, but emaciation in such cases was extreme.

Here we are also faced with the problem of gross obesity and have used complete starvation up to a period of 90 days in a number of cases. It must be realized that these patients are at risk, as most of those we have seen have E.C.G. changes suggesting myocardial ischaemia and some have presented in heart failure. However, we have had no fatalities. Postural hypotension has been the main side effect, which on reflection probably affected me as a prisoner of war. The serum uric acid has risen to levels of $20 \mathrm{mg} / 100 \mathrm{ml}$ and we now use allopurinol. Ketosis has not been a problem, nor have we encountered hypoglycaemia. No electrolyte disturbances have been observed. Most of these patients have difficulty at times in excreting water, and we commonly use a diuretic, taking care to avoid potassium depletion.

While I should avoid this treatment in hepatic or renal failure and perhaps in diabetes mellitus, heart failure in our experience is not a contraindication. In fact, this is the reason we have used this regimen in several patients.- I am, etc.,

Memorial Hospital,

D. A. Ballantyne Hastings. New Zealand

\section{Congenital Hip Dislocation}

SIR,-I was most interested to read $\mathrm{Mr}$. Geoffrey Walker's cogent article on "Problems in the Early Recognition of Congenital Hip Dislocation" (17 July, p. 147). I wish to support his views wholeheartedly and, if I may, to underline some of the points he raises.

Many of us practising paediatric orthopaedics are concerned about the continued presentation in our clinics of patients suffering from dysplastic hips, despite the widespread belief that early neonatal screening has solved this problem once and for all. We feel that the Department of Health and Social Security's publication on this topic is due for early revision, particularly in view of the possible medicolegal implications. The following relevant points need emphasis.

(1) There exist two main aetiological types of congenitally dysplastic hips. Firstly, the relatively common unstable hip at birth, due to hypermobile joints and hypotonia, which responds well to neonatal splintage, and secondly; the rarer primary acetabular dysplasia, probably genetically determined. This latter is often a difficult group to diagnose and does not necessarily benefit from the regimen of early splintage.

(2) One source of misdiagnosis by inexperienced and even experienced observers is the small group of babies who have fully dislocated, irreducible hips where the von Rosen sign is negative and indeed the limited abduction sign is negative, too.

(3) We consider that a child reported by 
any observer in the neonatal period to have a click should be treated with prophylactic abduction splintage.

(4) It should be routine practice to observe carefully the hips of any children who present with a congenital foot deformity, whether this be calcaneus or equinus, as often these children have associated hip dysplasia.

(5) We consider that some system of screening during a child's first 12 months of life should be established by public health and infant welfare clinics. We appreciate there may be administrative difficulties, but nevetheless the detection of an unstable hip at six months as compared with 16 months greatly influences treatment and prognosis.

May I stress that, notwithstanding the points raised, von Rosen and Barlow's pioneer work on early screening must receive full acknowledgement. Our concern now is to tighten the net further during the first 12 months of life.-I am, etc.,

\section{ROBERT OWEN}

Robert Jones and Agnes Hunt Orthopaedic Hospital, Oswestry, Salop

SIR.-I must congratulate Mr. Geoffrey Walker on his important and timely article on "Problems in the Early Recognition of Congenital Hip Dislocation" (17 July, p. 147).

Having had personal humbling experience of an eight-month-old child referred to me with frank dislocation of the hip, after finding out that at birth I had examined this child for a mild calcaneo valgus deformity of her foot, I am certain that there are two aethiological types of congenital hip dislocation. My colleague, Mr. Robert Owen, brought this to our notice. 1 In this area we have certainly seen cases present after six months who had been examined by skilled medical personnel at birth and found to have normal hips.

As Mr. Walker states, the memorandum publirhed by the Ministry of Health in 1966 has led most people to believe that full hip examination in the neonate would eliminate any cases of congenital dislocation of hip presenting later. I am glad that $\mathrm{Mr}$. Walker's paper has again brought to our notice that this is not completely so and that all cases with any suspicion of even a mild congenital foot deformity should be followed through until they are walking, to make certain that acetabular dysplasia is not present.-I am, etc.,

\section{P. H. CORKERY}

Prince Edward War Memorial Hospital Rhyl

Owen, R.. Fournal of Bone and foint Surgery,

\section{Tuberous Sclerosis and the Lungs}

SIR.-I would like to point out a misconception in your otherwise interesting and informative leading article on "Tuberous Sclerosis and the Lungs" (10 July, p. 64). Although various mesodermal tumours are seen in patients with this rare disease, it is not true that "Liposarcomata are almost exclusive to tuberous sclerosis." In neither the study of 103 cases of liposarcoma by Enzinger and Winslow in America ${ }^{1}$ nor in our own series of 85 cases from the Westminster Hospital ${ }^{2}$ is the association of liposarcoma and tuberous sclerosis seen. These papers represent the largest series of liposarcomata on both sides of the Atlantic. Liposarcomata are extremely rare in childhood $^{3}$ but the associated mesodermal tumours of tuberous sclerosis commonly present in children.

Liposarcoma is one of the most important of the soft tissue sarcomata both because it is one of the most common and because the chances of cure are often good with a five year survival of $64 \%$. It may occur in association with tuberous sclerosis but it is much more commonly found without it.-I am, etc.,

\section{Meyerstein Institute of Radiotherapy, Middlesex Hospital, \\ 1 Enzinger, F. M., and Winslow, D. J., Virchows Archiv für pathologische Anatomie und Physio- logie und fur klinische Medizin, 1962, 335, 367. 2 Spittle, M. F., Newton K. A., and Mackenzie, D. H., British fournal of Cancer, 1970, 24, 696. delphia) S. L., and Stout, A. P., Cancer (Phila-}

Margaret F. SpitTle

SIR,-In your recent leading article on tuberous sclerosis and the lung (10 July, p. 64) you state "Liposarcomata are almost exclusive to tuberous sclerosis."

These are uncommon tumours but neither my colleagues nor I have noticed or heard of any such an association. The most recent authoritative text on soft tissue tumours states "they (liposarcomata) are not related to trauma or any other recognized aetiological factor." Other leading authorities on tumour pathology also fail to mention any association.

Your statement appears to be a quotation from a recent paper by Dwyer et al..$^{2}$ and as they make clear it refers to a paper on liposarcomata of the kidney by Fish and McLaughlin. ${ }^{3}$ Renal liposarcoma is an extraordinarily rare tumour and, in fact, the great majority of liposarcomata arise in other sites. . Tuberous sclerosis may well be associated with the renal liposarcomata ${ }^{3}$ but does not appear to be associated with extrarenal liposarcomata.

I trust you do not think this is too much of a pathologist's quibble. Your leading articles carry considerable authority and it may well be, as a result of the one on tuberous sclerosis, that the relatives of patients with these tumours are subjected to needless investigation of, and much anxiety about, the possibility of a concealed hereditary disease. - I am, etc.,

\section{R. G. M. LETCHER}

Bland-Sutton Institute of Pathology,
Middlesex Hospital Medical School,

London $\mathbb{W} .1$

1 Atlas of Tumour Pathology, Second Series, Fascicle I, 1967, p. 116.

Dwyer, J. M., Hickie, J. B., and Garvan, J., of U G. W., and McLaughlin, W. L., fournal

\section{Bullous Lesions in Poisoning}

SIR,-We have read Dr. C. M. Ridley's paper on "Bullous Lesions in Nitrazepam Overdosage" (3 July, p. 28) with unusual interest. $\mathrm{He}$ has performed a valuable service in drawing attention to the variety of causes of these lesions in unconscious patients and in concluding "that the bullae represent a reaction to pressure and hypoxia in the skin of the unconscious patient."

We note that his patient had bullae (is it no longer permissible to call them blisters? on "the left side of the face, left hand and wrist, and left breast" (our italics). We found no difficulty in placing a subject in a position in which these parts were subject to considerable pressure (Fig.). From evidence we collected in four cases of $\mathrm{CO}$ or barbiturate poisoning that came under our care ${ }^{1}$ because there had been ischaemic damage of muscle and nerve, as well as of skin we came to the conclusion that the ischaemic lesions occurred only where there was considerable

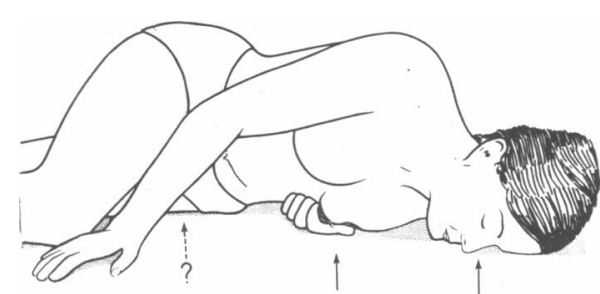

pressure. In this we were about 150 years behind the times; Napoleon's surgeon, Larrey, knew all about it. What puzzles us is that Dr. Ridley does not mention blistering over the left great trochanter; hence our question mark. But he did not, almost certainly because he could not, describe the position in which his patient was found. If it had been what we postulate, it was possible that the upper part of the body was lying on a hard surface and the pelvis on something soft, such as a pillow.

We strongly support his view that it is the combination of pressure and hypoxia that does the damage; the poison that causes unconsciousness is in no way specific.

We are indebted to the Institute of Orthopaedics for placing the facilities of its photographic department at our disposal.

-We are, etc.,

H. J. SEDdON

London W.1

A. J. D. HowsE

1 Howse, A. J. D., and Seddon, H. J., British Medical fournal, 1966, 1, 192.

SIR,-I read with great interest the article by Dr. C. M. Ridley on "Bullous Lesions in Nitrazepam Overdosage" (3 July, p. 28). This raises the question of the origin of these blisters and stimulates me to report a case of barbiturate blistering which I think may shed some light on the aetiology of these lesions.

A 50-year-old man took an overdose of about $25200 \mathrm{mg}$ amylobarbitone capsules and a few amitriptyline tablets on 5 June. He was admitted to hospital deeply unconscious and remained comatose for just over 24 hours after this. On admission to the psychiatric unit here on 8 June blisters surrounded by an erythematous margin were visible over the left acromion process, opposing aspects of the knees, and the inner aspects of the dorsa of the feet and on the lateral aspect of the left foot. By 5 July the blistering and ulceration had healed on the left acromial region and similar lesions on the outer aspect of the left foot were well advanced in healing. However, the ulcers which had been associated with the blistering on the opposing surfaces of knees and 